\title{
Thinking on Implementation of Green Management by Enterprises Xiaosheng Lei
}

Hubei University of Chinese Medicine, Wuhan Hubei, 430000, China

Key words: Business management, Green Marketing, Green Management, Ecosystem.

\begin{abstract}
With the development of modern society, how to protect our ecological environment and homeland In 1990s, a wave of greenization emerged around the globe. This paper analyzes the content and importance of green management of enterprises and puts forward suggestions and measures for preventing greenwash behavior.
\end{abstract}

\section{Introduction}

Green management is a hot topic of management in recent years. Since 1960s, a series of vicious ecological events have occurred on the earth, including greenhouse effect, damage of ozone layer, nuclear leakage, clenbuterol event, BSE, Sudan red, oil leakage pollution, melamine and leakage of toxic gas. They have not only damaged the ecological environment of human beings seriously, but also endangered their survival. People had to think about how to protect our ecological environment and homeland and achieve sustainable development of the society. In 1990s, people realized that green products were good for human health and environmental protection. A wave of greenization swept the globe. Consumers considered the purchasing of green products as fashion and enterprises implemented green management. Green thought has influenced various aspects of social life. Such influence is manifested in enterprise management, i.e. green management.

The implementation of green management in enterprises has a history of over 20 years. A college professor in Wuhan made a six-year investigation on the processing and application of urban kitchen waste and found that annual profit of illegal cooking oil was up to 1.5 to 2 billion Yuan. The conclusion was that "you must have eaten illegal cooking oil." Some pharmaceutical enterprises make technical gelatine into capsules. Chrome content of drugs is out of limit, which endangers human health. Similar examples worth thinking. How should enterprises shoulder social responsibility ${ }^{[1]}$ and actually implement green management?

\section{Connotations of green management of enterprises}

Green management is a comprehensive concept combining the concept of ecological environmental protection and social concept. Green management of enterprises means that environmental protection concept is integrated into enterprise management and environmental protection requirements are considered in various aspects and at each level of enterprise management. Greenization is implemented in product research and development, design, production and sales and the process from raw material to production and from production to recovery processing without any pollution. Its basis is green products and industry. With the emergence of global green wave, green standard has consistency around the globe.

\section{Importance of implementation of green management by enterprises}

The implementation of green management by enterprises not only meets the trend of social development and interests of consumers, but also facilitates enterprise survival and development. The 
implementation of green management by enterprises is a win-win strategy. Its importance is self-evident.

1. It is good for the protection of natural resources and sustainable development of human. Economy cannot develop at the cost of health and environment. In the past, some enterprises implemented extensive operation. While gaining economic benefits, they discharged waste water and gas illegally which polluted the environment and caused vicious environmental pollution such as dead fish floating in lakes. Green management of enterprises is good for both the protection of ecological resources and long-term development of the society.

2. It is good for improving survival and competitive ability of enterprises. To run an enterprise, it is required to gain the approval of the administration for industry and commerce and meet the standard of production environment and pollutant discharge specified by law. That is to say, enterprises exist under the premise of performing social obligations. Implementing green management and shouldering social responsibility is good for improving the popularity and social reputation of enterprises, gaining the trust of more consumers, improving the competitiveness of products and gaining more social returns and profits in the long term.

3. It meets interests of consumers and social development trend. With the development of social economy, the improvement of living standard and health consciousness of human beings, green thought forms an irresistible wave in the world. People buy green food and publicize green consumption. When enterprise managers realize green development trend, grasp the opportunity brought by the trend, study the psychology of consumers, implement green management and develop green products in time, new vitality will be injected into enterprises inevitably.

\section{Main contents of green management of enterprises}

Green management thought of enterprises includes the following contents:

\section{Advocate the concept of green operation and establish green value.}

Value is the guiding thought of business activities of enterprises and the core of modern corporate culture. Establishing green value means that enterprises pay attention to the operational concept of ecological protection, conduct green management over product research and development, production, packaging and marketing and regard resource conservation and environmental protection as a strategy for long-term development of enterprises. Therefore, enterprises should set up green corporate culture, advocate the concept of green operation, cultivate environmental awareness of employees, coordinate enterprise development and environmental protection and social development and use the production of green products as the approach for improving economic interests.

\section{Adopt green technologies and develop green products.}

The core of green management is the implementation of green technologies. Green technologies refer to technologies that can save energy and reduce environmental pollution. Green technologies include pollution prevention technology and terminal processing technology. Pollution prevention focuses on the prevention of source. For example, enterprises use new technologies to process or avoid the emission of waste gas and water in the production process. Enterprises with zero radiation using wind energy and solar energy to generate electricity are examples. Terminal processing is a technology isolating and incinerating production wastes and reducing environmental pollution, including recycling of waste products. Green technology is the key to the construction of green enterprises. Enterprises should seek for methods and technologies solving the problem of resource consumption and environmental pollution in production so as to protect natural resources and ecological environment and improve the market competitiveness of green products.

Green products are the result of the application of green technology. Green products include pure natural objects and their processed goods such as natural ecological clothes made of cotton, fiber, silk and bamboo charcoal. The use of green products is safe and healthy for human body and harmless to the environment. The development of green products includes green brand, packaging, service and 
reputation etc. The development process of green products is key to the performance of environmental protection by enterprises. The production process and products themselves are energy-saving, low-pollution, non-toxic, reproducible and recyclable. To enter the market, green products should pass the certification and obtain "green label". 389 kinds of pollution-free green food were launched in China in 1995. The number of green food reached 23,100 in 2015. There were over 9500 green food production enterprises in $2015^{[2]}$. The future development of green products in China has a big potential market. Green products impel the consumption idea and sense of business of the public to be changed. Enterprises should strengthen technical research and development and publicity of green products and meanwhile improve environmental and safety awareness of consumers. Good green products can be favored by consumers.

\section{Set up concept of green brand and implement green marketing.}

As the concept of green consumption prevails, green market is expanded rapidly. Enterprises should pay attention to create green brand so as to gain advantages in market competition. The creation of green brand should start with the design of green products. Different from traditional design, green design regards the reduction of energy consumption, convenience for recycling, ecological environmental protection and product quality and properties as equally important design indicators in the stage of product conception and guarantee that the product can save energy and prevent pollution effectively in production, meet consumer demands and meanwhile bring returns to enterprises.

Green marketing means that enterprises emphasize ecological equilibrium and establish the mechanism of green operation to make enterprise development and interests of consumers and the society consistent in the marketing process such as market survey, product research and development, price setting and promotion under the guidance of green concept of environmental protection. The recovery and treatment of wastes should also be considered in after-sales service so as to reduce environmental pollution. For example, for green marketing of automobile dealers, considering the environmental pollution caused by automobile exhaust, each owner of the car sold by them planted a green tree by the road. The tidy green belt by the road not only records their sales performance, but also represents their contribution to environmental protection.

\section{How to supervise green management of enterprises}

To implement green management, apply green technologies and develop green products, enterprises require capital investment. In the short term, this might increase their costs and reduce products. However, this will bring more social returns to enterprise development in the long term. Robbins has investigated five security funds abiding by moral and social responsibility ${ }^{[3]}$ and found that their performance was equal to that of other funds. In recent years, many enterprises have implemented green management, paid attention to the concept of environmentally friendly production, produced environmentally friendly products and gained the favor of the society. However, individual problems have occurred. Some enterprises conducted behaviors harmful to the environment in the name of green. For example, some chemical enterprises seriously polluted groundwater resources and their exhaust gas emission caused air contamination etc. All these behaviors are called as greenwash behaviors. Even to this day, greenwash behaviors occur occasionally. How to prevent the occurrence of greenwash behaviors of enterprises? How to supervise the implementation of green management of enterprises? The following suggestions are made:

1. Strengthen the establishment of laws and regulations on environmental protection of enterprises. To protect the environment and benefit descendants, it is required to establish relevant complete laws on environmental protection and promote smooth implementation of environmental protection work through the mandatory effect of law.

2. Improve green product supervision system. Improve means for monitoring the production and quality of green food technically. Strengthen administrative regulations and supervision and inspection on green food. Realize whole-process management over food security, including raw 
materials, processing and supervision and inspection on final products. Replace traditional inspection which only emphasizes finished products. Avoid the phenomenon of offering chaff for grain.

3. Promote supervision of the society and media on green management. In 2011, "Zhi Chu Chuang Wai" civil food security network established by college students occurred in China, which publicized problems found in spot check on various food in various regions in China and reminded people of paying attention to food security. It is expected that a professional authoritative institution can release information about green food and unsafe food periodically, implement the system of active product quality report and release warning information of defective products periodically. Meanwhile, a platform can be provided for enterprises so that enterprises can report the implementation status of green management actively through the website.

4. Adopt ISO international environmental standard system. Though environmental management standard established by ISO is optional, to meet the standard, enterprises need to undertake social responsibilities actively and develop a comprehensive environmental management system so as to abide by the rule.

5. Include green behaviors of enterprises as the basis of ranking top hundred enterprises. It is required to regard green management of enterprises as an important weight coefficient to evaluate the rank of top hundred enterprises so as to promote green management of enterprises.

\section{References}

[1] Zhou Sanduo, Management, the Third Edition, Higher Education Press, February 2010.

[2] Xinhuanet, November 21, 2015.

[3] Stephen Robbins, Management, the 9th Edition, Tsinghua University Press, June 2009. 